\title{
Preferences of Dental Students towards Teaching Strategies in Two Major Dental Colleges in Riyadh, Saudi Arabia
}

\author{
Eman M. AlHamdan, ${ }^{1}$ Huda I. Tulbah, ${ }^{1}$ Ghaida A. AlDuhayan, ${ }^{2}$ and Lamees S. AlBedaiwi ${ }^{3}$ \\ ${ }^{1}$ Department of Prosthetic Dental Sciences, College of Dentistry, King Saud University, P.O. Box 60169, Riyadh 11545, Saudi Arabia \\ ${ }^{2}$ Armed Forces Hospital, King Abdulaziz Naval Base, Jubail 35512, Saudi Arabia \\ ${ }^{3}$ Nayel Clinics, Riyadh 12473, Saudi Arabia
}

Correspondence should be addressed to Eman M. AlHamdan; ealhamdan_pros@yahoo.com

Received 7 May 2016; Accepted 5 July 2016

Academic Editor: Gwo-Jen Hwang

Copyright (C) 2016 Eman M. AlHamdan et al. This is an open access article distributed under the Creative Commons Attribution License, which permits unrestricted use, distribution, and reproduction in any medium, provided the original work is properly cited.

Objectives. To explore and compare undergraduate dental students' views and preferences towards various teaching strategies. Methods. A questionnaire was developed and distributed to 345 male and female undergraduate dental students from the two major dental schools in Riyadh (College of Dentistry, King Saud University [KSU], and Riyadh Colleges of Dentistry and Pharmacy [RCsDP]). Students' preferences for various components of the lecture courses were investigated. Descriptive and crosstab analyses were used to compare the students' preferences for each school and between genders; the chi-square test was used to measure the significance level $(P=0.05)$. Results. The majority of students preferred having the lecture schedule announced in advance. Females preferred morning lectures, whereas male students preferred afternoon lectures. Nearly half of the students thought that attending lectures should be mandatory; most of them were from KSU. Most of the students reported preferring a PowerPoint presentation lecture. The students, particularly female students, also preferred to receive lecture handouts and study materials before the session and to have practical demonstrations after the lecture. Conclusion. Teachers should consider students' opinions when constructing courses because this feedback would have a positive impact on the teaching environment and students' performance.

\section{Introduction}

One of the most serious challenges that dental educators face today is improving the learning environment and increasing the level of student satisfaction with the curriculum [1]. The current dental students represent a broad spectrum in terms of their cultures, experiences, personalities, and learning preferences and styles. This diversity presents a challenge for dental educators to meet the educational needs of all students, since student motivation and performance improve when teaching is adapted to their learning preference and styles [2]. Educators should consider accommodating different teaching modalities that will eventually reflect on their teaching effectiveness [3]. Effective teaching is critical for student learning, especially in professional fields such as dentistry. Teaching effectiveness can be defined as the extent to which the teaching activity fulfills its intended purpose, function, and goal [4]. The routine evaluation of teaching effectiveness is important to improving faculty, departmental, and institutional efforts [5]. Although many teaching approaches have emerged through the years, the "lecture," which dates to the mid-19th century, has been the predominant mode of instruction since universities were founded, and it remains the predominant form of teaching in education for health care professions $[6,7]$. The greatest advantage of lectures, in the opinion of faculty members, is the ability to share information with a large number of students [8]. Lectures will continue to be the main teaching strategy of choice for delivering the basic curriculum to as many students as will fit in a lecture theater because of the economic constraints on institutions, staff, facilities, and students [9].

Educational researchers postulate that everyone has a learning style and that if instruction is adapted to accommodate that style, improved learning is anticipated $[10,11]$. It is suggested that instructors should attempt to alter their methods of teaching so students with differing learning styles can have an opportunity to learn in an environment that is more 
conducive to their preferences [10]. Studies have researched students' views on academic preparation [12], the learning environment [13], the use of techniques [14], curriculum changes $[15,16]$, the impact of dental education on their stress level $[17,18]$, teaching effectiveness in classrooms and clinics [19], and the teaching styles and approaches [20]. The current belief is that students have opinions about the quality of the instruction that they receive [21]. Although extensive research has been performed on the effectiveness of teaching and learning strategies, there remains a lack of research exploring dental students' preferences for such strategies. Therefore, the purpose of this study is to explore and compare the undergraduate dental students' views and preferences about various aspects of teaching clinical and lecture courses in two major dental schools in Riyadh city, the College of Dentistry, King Saud University (KSU), and Riyadh Colleges of Dentistry and Pharmacy (RCsDP), and to compare the experience between males and females.

\section{Materials and Methods}

A self-developed questionnaire was prepared to determine students' preferences for teaching strategies used in lectures and clinics. The questionnaire was developed based on the knowledge collected by the researchers from literature review. It was written in English, with the cover page presenting the consent form and an explanation about the purpose of the study. Additionally, the confidentiality and sole use of the information for the mentioned purpose were ensured. The research design was registered at College of Dentistry's Research Centre (CDRC) and was reviewed and approved by the Ethical Committee (3334050/IR0003).

The questionnaire consisted of three sections. The first section included the following demographic data: gender, student level, and university. The second section was about lectures (preferred lecture length, time, method of lecturing, timing of lecture schedule announcement, and attendance). The third section was about the study materials related to the lectures and clinical sessions (preference of materials' provision before the session, having an interactive session, and having handouts and clinical demonstration after the lecture).

Most of the questions were answered using a 3-point Likert scale ( 1 = agree, 2 = neutral, and $3=$ disagree $)$.

The questionnaire was distributed to undergraduate male and female dental students in the two major dental schools in Riyadh city, the College of Dentistry, King Saud University (KSU), and Riyadh Colleges of Dentistry and Pharmacy (RCsDP). A stratified random sampling method was applied to collect a sample of 345 participants, representing $27.4 \%$ of the dental students at the two schools (total of 1259 students).

A pilot study was performed on 30 students at KSU to determine the acceptability and clarity of the questionnaire and to confirm its validity. Depending on the comments, minor changes were made before questionnaire distribution.

Data were analyzed using Statistical Package for Social Sciences (SPSS) version 16. Descriptive and crosstab analyses were used to compare the students' preferences for each

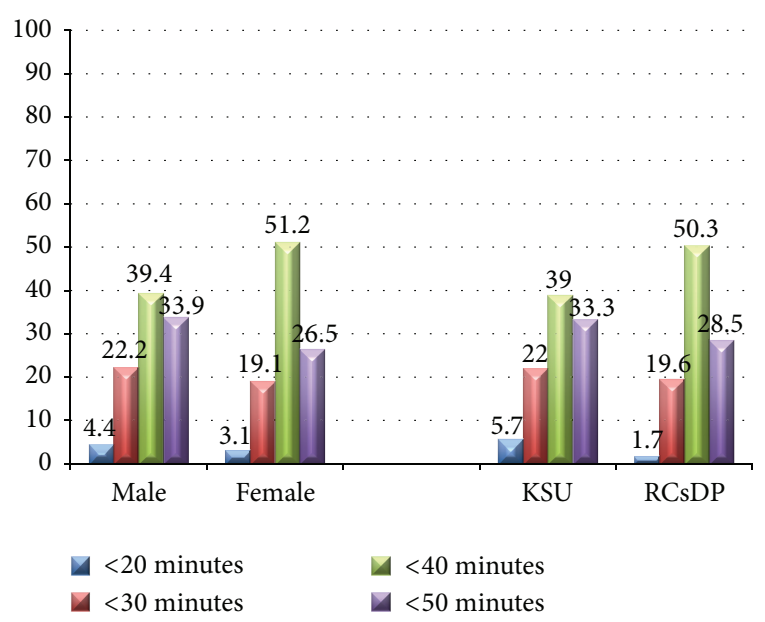

FIGURE 1: Percentage of dental students' preferences regarding lecture length.

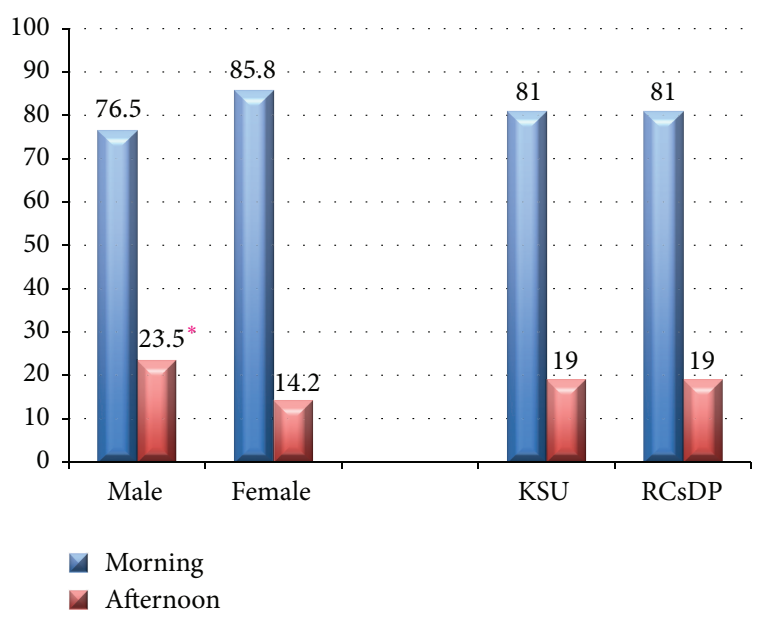

Figure 2: Percentage of dental students' preferences regarding lecture timing $\left({ }^{*} P<0.05\right)$.

school and between males and females in general. The chisquare test was used to measure the significance level $(P=$ 0.05).

\section{Results}

A total of 345 students participated in the study; 159 (46.1\%) were from KSU and 186 (54\%) were from RCsDP. There were $183(53 \%)$ males and $162(47 \%)$ females.

Approximately $45 \%$ of all dental students agreed that the preferable lecture length should not exceed 40 minutes, and there were no significant differences between males and females or between the dental colleges (Figure 1).

Many students (81\%) preferred morning lectures; however, more male students preferred afternoon classes (23.5\%) compared to females (14.2\%), which was statistically significant $(P<0.05)$ (Figure 2).

PowerPoint lectures were selected as the preferable method of lecturing (79.4\%). However, more RCsDP students 


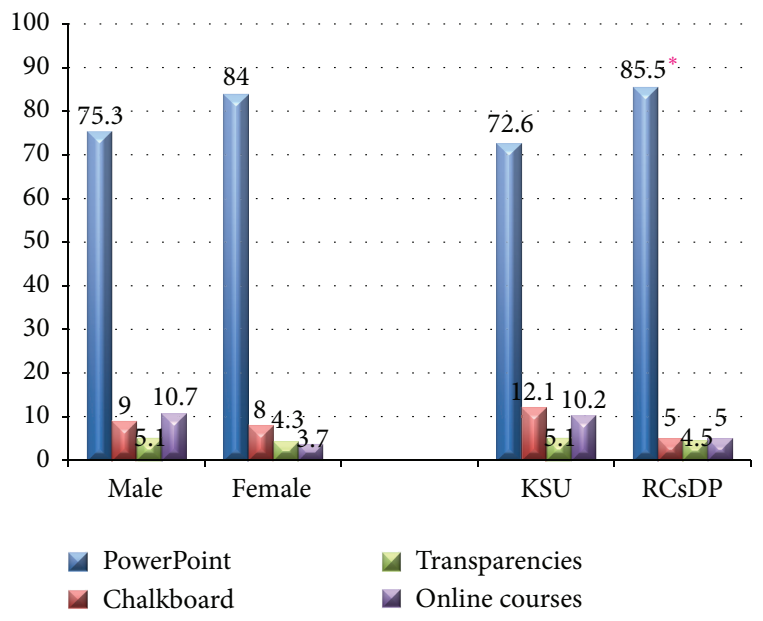

Figure 3: Percentage of dental students' preferences regarding lecturing method $\left({ }^{*} P<0.05\right)$.

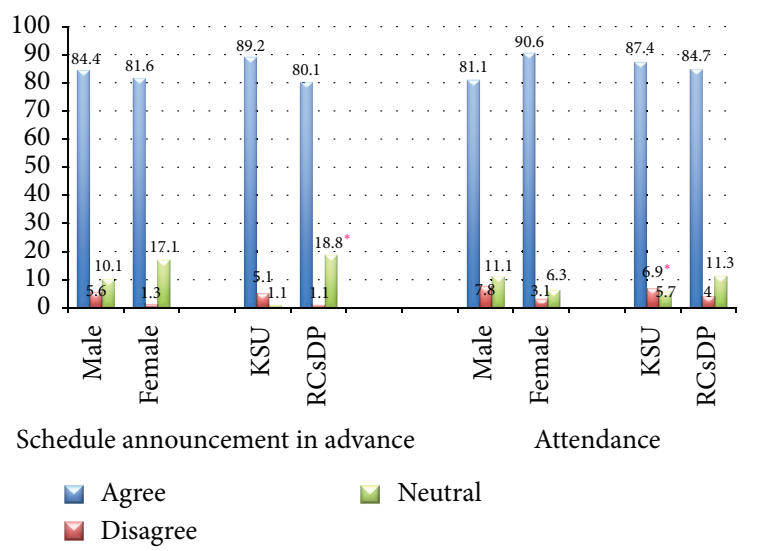

Figure 4: Percentage of dental students' preferences regarding schedule announcements and attendance $\left({ }^{*} P<0.05\right)$.

preferred this method than KSU students, which was statistically significant $(P<0.05)$ (Figure 3 ).

The majority of students $(83 \%)$ preferred having the lecture schedule announced in advance. RCsDP students were more neutral about the timing of schedule announcement (Figure 4).

It was found that $43 \%$ of all students thought that attending lectures should be compulsory. On the other hand $31 \%$ thought that it should not be; $40 \%$ of them were from KSU compared to $24.5 \%$ from RCsDP, which was statistically significant $(P<0.05)$ (Figure 4).

Sixty-seven percent of the students preferred to be given material to study before the session and to have an interactive session. No significant differences were detected between the groups (Figure 5).

Approximately $86 \%$ of all students preferred to have lecture handouts; however, more female students preferred handouts (90.6\%) compared to males (81.1\%). Although the male students were more neutral in their opinions about the handouts (11.1\%) than the females (6.3\%), this difference was statistically significant $(P<0.05)$ (Figure 6).

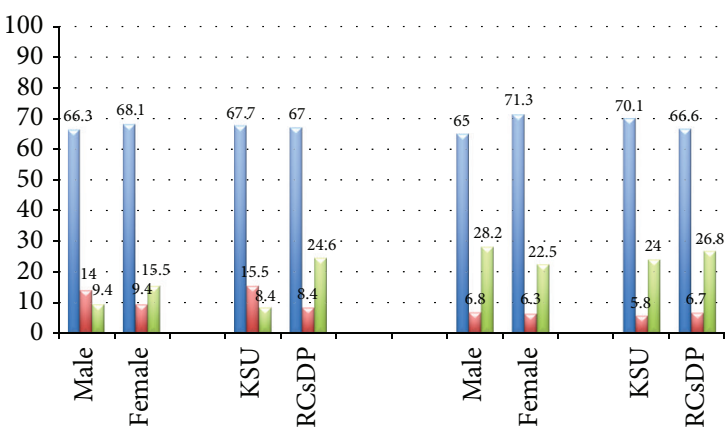

Provision of material before the session Interactive session

$$
\begin{aligned}
& \square \text { Agree } \\
& \square \text { Disagree }
\end{aligned}
$$

FIgURE 5: Percentage of dental students' preferences regarding having access to materials before the session and interactive sessions.

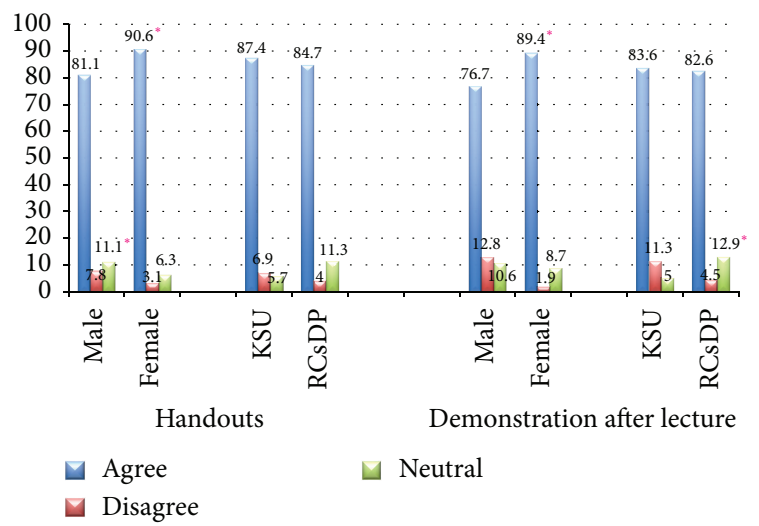

Figure 6: Percentage of dental students' preferences regarding handouts and demonstration after the lecture $\left({ }^{*} P<0.05\right)$.

Moreover, $82 \%$ of the students, most of whom were females (90\% compared to $77 \%$ males), agreed to have a practical demonstration conducted after the lecture, while RCsDP students were more neutral (13\%) than KSU students $(5 \%)$ on this topic. This finding was statistically significant $(P<0.05)$ (Figure 6).

\section{Discussion}

As the learning preference of dental students has drastically changed over the last several years as a result of the diversity of the student's cultures, experience, and personality, this study was conducted to help educators improve the learning environment and increase the level of student satisfaction. The study was conducted in two major dental colleges in Riyadh area, Saudi Arabia. The selection of these two colleges was based on the fact that the College of Dentistry, KSU (1975), is the first public college in the Gulf Area, and Riyadh Colleges of Dentistry and Pharmacy (2004) is the first private dental school in the Kingdom.

The dental education system is nearly identical in both schools; both are comprised of one preparatory year followed 
by five years of dental specialty, but KSU operates on an annual system, while RCsDP adopts a semester system.

A stratified random sample was used in this study. This method provides greater precision and is more representative than a simple random sample of the same size. In addition, it reduces the sample selection bias and helps ensure that the sample accurately reflects the population being studied.

A 3-point Likert scale was used in this study. Many researchers have found that ratings using scales of 2, 3, 5 , and 7 points are equivalently reliable [22-24]. In this study, our interest was to learn the direction of students' opinions rather than the intensity of their beliefs, which is best accomplished with either a 2- or a 3-point Likert scale. In addition, a questionnaire using a 3-point Likert scale can be completed faster than scales with more options, helps prevent responders from making random choices, avoids contradictory opinions, and is scored easily.

4.1. Lecture Length and Timing. The lecture is possibly the most iconic and frequently criticized element of university education [25]. In the present study, lecture length in both dental schools is 50 minutes and the lecture timing is the same. Lectures are given in the morning (8-8:50 a.m.) and in the afternoon (1-1:50 p.m.). Some of the courses at RCsDP provide lectures as a block of 4-6 hours. The highest percentage of dental students in this study (45\%) agreed that the optimal lecture length should not exceed 40 minutes. This is in agreement with many previous studies. Parolia et al. [26] found that the majority of students preferred that the lecture length should be thirty to forty minutes. The students' recommendation of lecture time not exceeding 40 minutes is supported by many previous research studies. Arredondo et al. [27] recommended that the lecture time should be no longer than forty-five minutes. Bryner Jr. [28] indicated that a 20-minute lecture was equal to the classic 50 -minute lecture in terms of the amount of information that the audience retained. Studies have suggested that a student's attention will decrease no matter what you do or what you talk about and that the rate of this decrease depends on several variables, including the difficulty of the subject. Middendorf and Kalish [29] broke up a one-hour lecture into minutes and marked when a university student's attention decreased. They found that, after an initial 3-5 minutes of settling, the students are optimally focused on the subject for 10-18 minutes. After this optimal period of attention, there is a lapse that occurs no matter how good the lecturer or how compelling the material is. Eventually, attention returns, but it decreases in the 3-4-minute rush towards the end of the lecture. Burns [30] found a similar time frame of optimal focus; he tested students on their recall in a 20minute presentation and found that students remembered the most from the beginning of the lecture. By the 15minute mark, they were almost completely "zoned out." It was recommended that teachers insert "change-ups" at various points in their lectures to regrab the attention of the students.

In the current study, a high percentage of students (81\%) preferred morning lectures. This result is not in agreement with a previous study by Barron et al. [31], who reported that the mastery skills of the below-grade-level students are affected by the time of day they receive the lecture. They found an overall increase in the mean scores for below-grade-level students who received instruction in the afternoon compared with those in a similar group who received instruction in the morning. In another study, Ammons et al. [32] investigated the effect of the time of day on the academic achievement of a general population of students. Although the researchers found that time of day plays a significant part in student achievement, not all students performed best at a single time of day. Instead, when students were taught at times that matched their learning style preferences, they scored significantly higher on lecture-related quizzes. This correlation was particularly strong in the case of students whose preferred learning time was the afternoon. In another study by Holloway [33], who studied dental students who were lectured alternately at the beginning and end of the day throughout a lecture series for which summary handouts were available, there was no reliable evidence that the students' performance was better after attending lecture in the morning compared to in the afternoon. As a group, they showed no preference for the late rather than early lectures, although some students favored the former while others favored the latter. Additionally, in a recent study by Rokade and Bahetee [34], 7\% of the students were totally inattentive to the morning lecture in contrast to $20 \%$ of the students during the afternoon lecture. They also found that memory for morning lectures can be improved 2-2.5 times by adding visual aids, while memory for afternoon lectures would require the addition of kinesthetic aids to improve; since most dental lectures contain visual aids (clinical pictures or laboratory steps) rather than kinesthetic aids, this could explain the high percentage of students who prefer morning lectures.

It was also reported in the current study that there is a statistically significant difference within gender groups, as more male students than female students preferred afternoon classes. This could be explained by the different after-school responsibilities of the female students compared to male students, whereby the females prefer to start early and finish early.

Based on the aforementioned results and to determine the best time of the day to deliver a lecture, we need to consider both the lecturer's efficiency and student's receptiveness as some lecturers like to deliver their lectures as early as possible (8 a.m.), whereas others prefer that lectures start after 10 a.m. The same applies to students. Morning birds like lectures as early as possible; night owls are only fully awake at 10 a.m. With this in mind, some changes can be applied to the time of lecture delivery when constructing the curriculum.

4.2. Method of Lecturing. Students tend to prefer the use of PowerPoint slides because they believe that the slides make their learning more efficient and help organize and structure their note taking. A number of studies showed that lectures with PowerPoint presentations improved students' performance [35-37]. However, these findings are in conflict with Susskind [38], who indicated that although the PowerPoint lectures were perceived as more organized and easier to understand, they did not enhance the students' performance 
on exams or the "students' studying behavior." In the present study, almost all of the lectures in both dental schools are delivered using PowerPoint format, which was selected as the preferable method of lecturing (79.4\% preferred this style). This is in agreement with a study by Parolia et al. [26], who found that the majority of the students in the study (63\%) preferred the PowerPoint lecture format over the chalkboard, which could have occurred because pictures of clinical and laboratory cases are an integral part of most topics in the dental college and can only be presented in PowerPoint form. When the RCsDP students were asked why they preferred the PowerPoint lecture format, it was found that they actually studied from those slides and that almost $90 \%$ of exam questions come from the slides. However, at KSU the faculty members use PowerPoint presentations only as a guide, with exam questions coming from textbooks. Moreover, KSU students spend their preparatory year on another campus and receive most of the lectures using transparencies and chalkboards, which may have made them more accepting of these media.

4.3. Schedule Announcement in Advance. It was reported that knowing the topic of the lecture in advance helps students prepare for class and provides clues about the readings [39]. In the present study, although the majority of students preferred having the lecture schedule announced in advance, students at RCsDP were neutral about it, which could be explained by the style to which students became accustomed in their previous education; as at KSU, all courses have outlines prepared listing all assigned lectures and lecturers ahead of time. These outlines are given to each student at the beginning of the academic year to help them prepare for lectures, which could explain their tendency to prefer this style. However at RCsDP, outlines are received later on in the academic year, which might have made some of them more neutral about the practice.

Another difference between the schools is the cumulative admission grade; KSU accepts students with a minimum high school grade of $90 \%$ compared to $80 \%$ at RCsDP, thus distinguishing the students in terms of their average prior educational achievement.

4.4. Attendance. Many researchers have examined the relationship between students' attendance and academic performance and have generally found that attendance matters for academic achievement [40-43]. Brauer [44] considered that absenteeism implies a direct negative effect on the learner. Additionally, for the rest of the class, absenteeism can increase the costs to the lecturer outside of the class time. In addition, Holloway [33] found that students had significantly more correct answers to questions based on the lectures that they had attended compared to questions on lectures that they had missed. A more recent study by Stanca [45] concluded that academicians are doing something useful for the students by giving lectures and that missing one lecture was associated with approximately a half-percentage point drop in the test score. This type of evidence has led some authors to call for measures to increase student attendance and to consider making attendance mandatory in some undergraduate courses.

In the present study, approximately $43 \%$ of dental students thought that attending the lectures should be compulsory, which is less than the result of a previous study by Parolia et al. [26], where $75 \%$ of dental students thought that attending lectures should be mandatory. Research studies have not shown that mandatory attendance ensures higher success rates for students. St Clair [46] examined and evaluated the research literature on the relationship between attendance and academic achievement. She found that attendance is linked to motivation and that required attendance does not guarantee high achievement. Moreover, an attendance policy will not guarantee attendance. "Classroom environments that engage students, emphasize the importance of students' contributions, and have content directly related to knowledge assessed will undoubtedly provide encouragement to students to attend regularly." However, St Clair's work dates back to 1999, and it could be argued that much has changed in the classroom and institutions of higher education over the past fifteen years. Although more recent studies on attendance have been conducted, these have focused on attendance for online courses and other issues.

Although the rules and regulations of both KSU and RCsDP state that lecture attendance is compulsory and absenteeism exceeding $25 \%$ entitles the student to be deprived of taking the final exam, a significant difference was detected within both colleges. Forty percent of KSU dental students compared to $25 \%$ of RCsDP students considered that the attendance should not be compulsory. This could be explained by the study cost between the colleges. RCsDP is a private college where students pay a high tuition; therefore, they want to take more advantage of these lectures, whereas students in KSU receive lectures for free.

Another explanation is that the RCsDP students take some of their lectures in comprehensive blocks of 4-6 hours, rather than one individual lecture per week, which might make them feel that attending a block is important and that the choice of attendance should not be left to the student.

Although the opinions about class attendance are at odds, research supports a strong link between classroom attendance and grades. Research indicates that attendance significantly explains the class grade and overall student performance. A student who frequently misses class will decrease their chances of receiving a high grade in a given course [47]. Research supports the idea that faculty should strongly encourage attendance by offering quality teaching and emphasizing the empiric relationship between grades and attendance [48].

4.5. Providing Materials before the Session to Encourage an Interactive Session. Newble and Cannon [49] described active learning as a process that encourages students to interact with the material being presented. Interactive learning may also have the added benefit of creating an internal locus of causality within learners, which is an important constituent of intrinsic motivation. It was also found that downloading lecture slides before class improves students' examination performance by $3.48 \%$ [39], suggesting that instructors could 
help students improve their academic performance by supplying PowerPoint slides. In the present study neither RCsDP nor KSU lecturers provide students with lecture material in advance; therefore it was not surprising that the majority of students in this study preferred to receive material to study before the session so they could engage in an interactive session.

4.6. Handouts. Researchers have different views about the distribution of handouts or lecture summaries. Early studies found that the distribution of handouts allows students to concentrate during the lecture instead of working on taking notes, thus making the class more interactive and producing a positive effect on students' academic performance [50-52].

Conversely, Brazeau [53] mentioned that students too often rely entirely on the handouts instead of learning from the assigned readings or they become passive listeners. This affects their opportunity to develop their own strategies for organizing information according to their own perspective, which is an important element in facilitating learning. Finally, the availability of complete notes may reduce the incentive for students to attend class because all of the information is presumably available in the handout.

In the present study, the majority of students preferred to have handouts and more female students preferred them compared to males. It was shown in a previous study that females are unimodal learners, preferring a single learning style, whereas males are multimodal learners, preferring different varieties of learning styles. In addition, learning by reading was preferred by a higher percentage of females compared to males, which might explain the female preference to have handouts compared to males [54].

4.7. Demonstration after Lecture. In the present study, the majority of the students agreed to have a practical demonstration that was conducted after the lecture, which is in agreement with the survey done by Parolia et al. [26]. An explanation for this could be that students can correlate the procedure with the lecture, resulting in a better application of the theoretical knowledge. In this study, female students agreed more than males that the demonstration should be performed after the lecture. This could be due to the differences in the learning styles and personalities between males and females; females like to be prepared ahead of time to avoid embarrassment. It was reported that males have no problem with being immediately corrected in front of others but that females mostly prefer to be corrected in private at a later time [55].

RCsDP students were more neutral than KSU students about the timing. Students in KSU dental college are used to having a demonstration after the lecture because that is the usual system that has been followed by the school in all practical courses.

\section{Limitations}

Limitations of this study include but are not restricted to

(1) the focus on only one aspect of the dental teaching process, the lecture; further research on clinical and laboratory elements of dental education should be conducted;

(2) the different cultural backgrounds of the students;

(3) the different learning backgrounds and expectations of the students, since they graduated from different high schools;

(4) differences in students' learning styles, which are a composite of cognitive, affective, and physiological characters that determine how a learner perceives, interacts with, and responds to the learning environment [56].

\section{Conclusions}

Despite several limitations, this study illustrated the following:

(1) Dental educators will need to reevaluate the lecture length to improve the efficiency of teaching.

(2) Lectures should be performed in ten-to-fifteenminute blocks, which could involve changing the pace every fifteen minutes or so to relieve monotony and recapture students' interest.

(3) During lecture delivery, lecturers should expect brief lapses in attention from their students and plan accordingly by offering minilectures with discussions or other activities.

(4) Teachers should consider the time of day when they plan and implement lectures as ongoing research indicates that the time of day plays a significant role in students' learning.

(5) Providing students with PowerPoint presentation slides ahead of time could help improve their academic performance.

(6) Teachers should arrange to perform a practical demonstration immediately after the lecture because this format has a very strong positive impact on information retention.

\section{Recommendation}

More research should be performed in this area to enable teachers, administrators, and policy-makers to make informed decisions about how to modify school schedules and classroom routines that maximize student learning.

\section{Competing Interests}

The authors declare that they have no conflict of interests regarding the publication of this paper.

\section{Acknowledgments}

The authors would like to express their deepest appreciation to Professor Nahid Y. Ashri, Department of Periodontics and Community Dentistry, College of Dentistry, King Saud University, for her help and advice in writing the paper. 


\section{References}

[1] A. L. Fang, "Utilization of learning styles in dental curriculum development," The New York State Dental Journal, vol. 68, no. 8, pp. 34-38, 2002.

[2] H. L. Lujan and S. E. Dicarlo, "First-year medical students prefer multiple learning styles," Advances in Physiology Education, vol. 30, no. 1, pp. 13-16, 2006.

[3] R. J. Murphy, S. A. Gray, S. R. Straja, and M. C. Bogert, "Student learning preferences and teaching implications," Journal of dental education, vol. 68, no. 8, pp. 859-866, 2004.

[4] L. Jahangiri, T. W. Mucciolo, M. Choi, and A. I. Spielman, "Assessment of teaching effectiveness in U.S. dental schools and the value of triangulation," Journal of Dental Education, vol. 72, no. 6, pp. 707-718, 2008.

[5] M. Endorf and M. McNeff, "The adult learner: five types," Adult Learning, vol. 2, no. 7, pp. 20-25, 1991.

[6] D. A. DaRosa, P. Kolm, H. C. Follmer, L. B. Pemberton, W. H. Pearce, and S. Leapman, "Evaluating the effectiveness of the lecture versus independent study," Evaluation and Program Planning, vol. 14, no. 3, pp. 141-146, 1991.

[7] J. C. Novak, "Active learning in continuing professional education: the challenge of leadership," New Directions for Adult and Continuing Education, vol. 1994, no. 56, pp. 63-81, 1992.

[8] D. A. Lake, "Student performance and perceptions of a lecturebased course compared with the same course utilizing group discussion," Physical Therapy, vol. 81, no. 3, pp. 896-902, 2001.

[9] R. Perrin and G. Laing, "The lecture: a teaching strategy through the looking glass," The E-Journal of Business Education \& Scholarship of Teaching, vol. 8, no. 1, p. 67, 2014.

[10] L. Suskie, "What are learning styles? Can we identify them? What is their place in an assessment program?" 2003, http:// www.sc.edu/fye/resources/assessment/essays/Suskie-2.27.03 .html.

[11] D. Robotham, "The application of learning style theory in higher education teaching," 1999, http://www2.glos.ac.uk/gdn/ discuss/kolb2.htm.

[12] N. W. Berk, J. M. Close, and R. J. Weyant, "Do student perceptions of their dental curriculum change over time?" Journal of Dental Education, vol. 62, no. 11, pp. 934-937, 1998.

[13] D. Henzi, E. Davis, R. Jasinevicius, W. Hendricson, L. Cintron, and M. Isaacs, "Appraisal of the dental school learning environment: the students' view," Journal of Dental Education, vol. 69, no. 10, pp. 1137-1147, 2005.

[14] D. M. Clark, O. J. Oyen, and P. Feil, "The use of specific dental school-taught restorative techniques by practicing clinicians," Journal of Dental Education, vol. 65, no. 8, pp. 760-765, 2001.

[15] P. Farge, J. Virieux, and J. Doury, "Student satisfaction with curriculum modifications in a French dental school," European Journal of Dental Education, vol. 4, no. 3, pp. 112-117, 2000.

[16] H. A. Ryding and H. J. Murphy, "Assessing outcomes of curricular change: a view from program graduates," Journal of Dental Education, vol. 65, no. 5, pp. 422-426, 2001.

[17] E. Barbería, C. Fernández-Frías, C. Suárez-Clúa, and D. Saavedra, "Analysis of anxiety variables in dental students," International Dental Journal, vol. 54, no. 6, pp. 445-449, 2004.

[18] A. K. H. Pau and R. Croucher, "Emotional intelligence and perceived stress in dental undergraduates," Journal of Dental Education, vol. 67, no. 9, pp. 1023-1028, 2003.
[19] D. J. Schönwetter, S. Lavigne, R. Mazurat, and O. Nazarko, "Students' perceptions of effective classroom and clinical teaching in dental and dental hygiene education," Journal of Dental Education, vol. 70, no. 6, pp. 624-635, 2006.

[20] S. Singh and S. Gautam, "Teaching styles and approaches: medical student's perceptions of animation-based lectures as a pedagogical innovation," Pakistan Journal of Physiology, vol. 5, no. 1, pp. 16-19, 2009.

[21] W. McKeachie, Teaching Tips: A Guidebook for the Beginning College Teacher, D.C. Health \& Company, Washington, DC, USA, 6th edition, 1969.

[22] A. W. Bendig, "Reliability and the number of rating-scale categories," Journal of Applied Psychology, vol. 38, no. 1, pp. 3840, 1954.

[23] S. Komorita and W. Graham, "Number ID scale points and the reliability scales," Educational and Psychological Measurements, vol. 25, pp. 987-995, 1965.

[24] E. R. Masters, "The relationship between number of response categories and reliability of Likert-Type questionnaires," Journal of Educational Measurement, vol. 11, no. 1, pp. 49-53, 1974.

[25] M. Hitchens and R. Lister, "A focus group study of student attitudes to lectures," in Proceedings of the 11th Australasian Computing Education Conference (ACE '09), vol. 95, pp. 93-100, January 2009.

[26] A. Parolia, M. Mohan, M. Kundabala, and R. Shenoy, "Indian dental students' preferences regarding lecture courses," Journal of Dental Education, vol. 76, no. 3, pp. 366-371, 2012.

[27] M. A. Arredondo, E. Busch, H. O. Douglass, and N. J. Petrelli, "The use of videotaped lectures in surgical oncology fellowship education," Journal of Cancer Education, vol. 9, no. 2, pp. 86-89, 1994.

[28] C. L. Bryner Jr., "Learning as a function of lecture length," Family Medicine, vol. 27, no. 6, pp. 379-382, 1995.

[29] J. Middendorf and A. Kalish, "The 'change-up' in lectures," The National Teaching and Learning Forum, vol. 5, no. 2, pp. 1-12, 1996.

[30] R. Burns, "Information impact and factors affecting recall," in Proceedings of the in the Annual National Conference on Teaching Excellence and Conference of Administration, Austin, Tex, USA, 1985.

[31] B. Barron, M. Henderson, and R. Spurgeon, "Effects of time of day instruction on reading achievement of below grade readers," Reading Improvement, vol. 31, no. 1, pp. 59-60, 1994.

[32] T. Ammons, J. Booker, and C. Killmon, "The effects of time of day on student attention and achievement," ERIC Document Reproduction Service ED348592, 1995.

[33] P. J. Holloway, “The effect of lecture time on learning," British Journal of Educational Psychology, vol. 36, no. 3, pp. 255-258, 1966.

[34] S. Rokade and B. Bahetee, "Morning lectures are better retained than afternoon ones: a pilot evaluation report of 1st MBBS anatomy students," Scholars Journal of Applied Medical Sciences, vol. 1, no. 6, pp. 843-847, 2013.

[35] R. B. Lowry, "Electronic presentation of lectures: effect upon student performance," University Chemistry Education, vol. 3, no. 1, pp. 18-21, 1999.

[36] A. Szabo and N. Hastings, "Using IT in the undergraduate classroom: should we replace the blackboard with PowerPoint?" Computers and Education, vol. 35, no. 3, pp. 175-187, 2000.

[37] S. Kask, "The impact of using computer presentations (CAP) on student learning in the microeconomics principles course," 
in Proceedings of the American Economic Association, Boston, Mass, USA, 2000.

[38] J. E. Susskind, "PowerPoint's power in the classroom: enhancing students' self-efficacy and attitudes," Computers and Education, vol. 45, no. 2, pp. 203-215, 2005.

[39] J. Chen and T.-F. Lin, "Does downloading powerpoint slides before the lecture lead to better student achievement?" International Review of Economics Education, vol. 7, no. 2, pp. 9-18, 2008.

[40] G. Durden and L. Ellis, "The effects of attendance on student learning in principles of economics," The American Economic Review, vol. 82, no. 2, pp. 343-346, 1995.

[41] S. Devadoss and J. Foltz, "Evaluation of factors influencing student class attendance and performance," American Journal of Agricultural Economics, vol. 78, no. 3, pp. 499-507, 1996.

[42] D. R. Marburger, "Absenteeism and undergraduate exam performance," The Journal of Economic Education, vol. 32, no. 2, pp. 99-109, 2001.

[43] P. Dolton, O. D. Marcenaro, and L. Navarro, "The effective use of student time: a stochastic frontier production function case study," Economics of Education Review, vol. 22, no. 6, pp. 547560, 2003.

[44] J. Brauer, "Correspondence: should class attendance be mandatory?” Journal of Economic Perspectives, vol. 8, no. 3, pp. 205-215, 1994.

[45] L. Stanca, "The effects of attendance on academic performance: panel data evidence for introductory microeconomics," The Journal of Economic Education, vol. 37, no. 3, pp. 251-266, 2006.

[46] K. L. St Clair, "A case against compulsory class attendance policies in higher education," Innovative Higher Education, vol. 23, no. 3, pp. 171-180, 1999.

[47] J. Brocato, "How much does coming to class matter? Some evidence of class attendance and grade performance," Educational Research Quarterly, vol. 13, no. 3, pp. 2-6, 1989.

[48] T.-F. Lin and J. Chen, "Cumulative class attendance and exam performance," Applied Economics Letters, vol. 13, no. 14, pp. 937942, 2006.

[49] D. Newble and R. Cannon, Handbook for Teachers in Universities and Colleges. A Guide to Improving Teaching Methods, RoutledgeFalmer, Taylor \& Francis Group, London, UK, 4th edition, 2000.

[50] J. Hartley, "Lecture handouts and student note-taking," Programmed Learning and Educational Technology, vol. 13, no. 2, pp. 58-64, 1976.

[51] W. R. Klemm, "Efficiency of handout 'skeleton' notes in student learning," Improving College and University Teaching, vol. 24, no. 1, pp. 10-12, 1976.

[52] K. A. Kiewra, "Students' note-taking behaviors and the efficacy of providing the instructor's notes for review," Contemporary Educational Psychology, vol. 10, no. 4, pp. 378-386, 1985.

[53] G. A. Brazeau, "Handouts in the classroom: is note taking a lost skill?" The American Journal of Pharmaceutical Education, vol. 70, no. 2, article 38, 2006.

[54] E. A. Wehrwein, H. L. Lujan, and S. E. DiCarlo, "Gender differences in learning style preferences among undergraduate physiology students," Advances in Physiology Education, vol. 31, no. 2, pp. 153-157, 2007.

[55] A. Ebrahimpourtaher, "Methodological preferences of engineering students in relation to EFL: Focus on gender," ProcediaSocial and Behavioral Sciences, vol. 70, pp. 841-852, 2013.
[56] J. W. Keefe, Learning Style Theory and Practice, National Association of Secondary School Principals, Reston, VA, USA, 1987. 


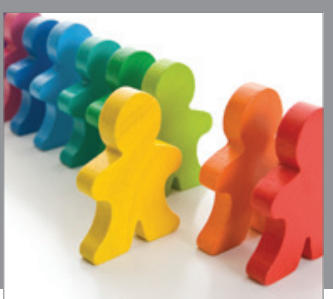

Autism

Research and Treatment
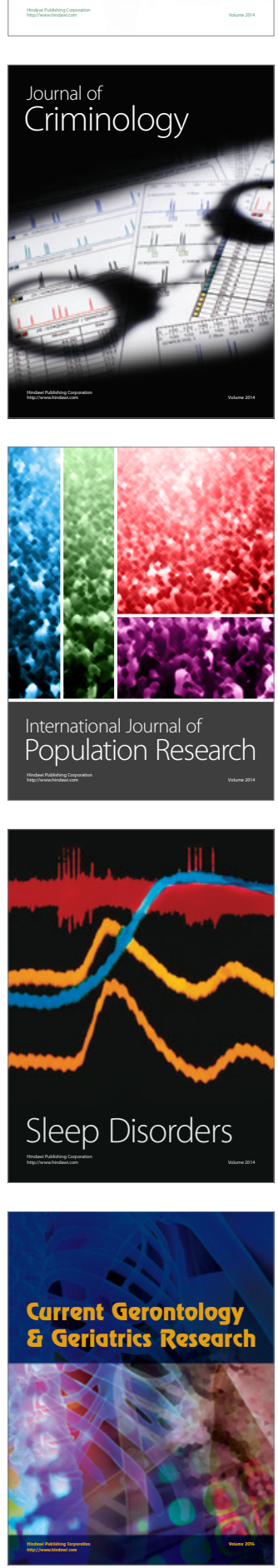

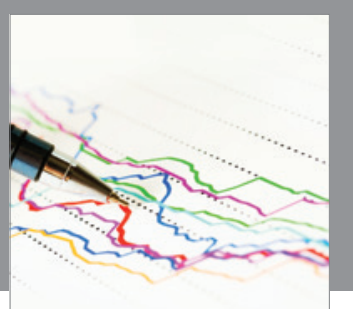

Economics

Research International
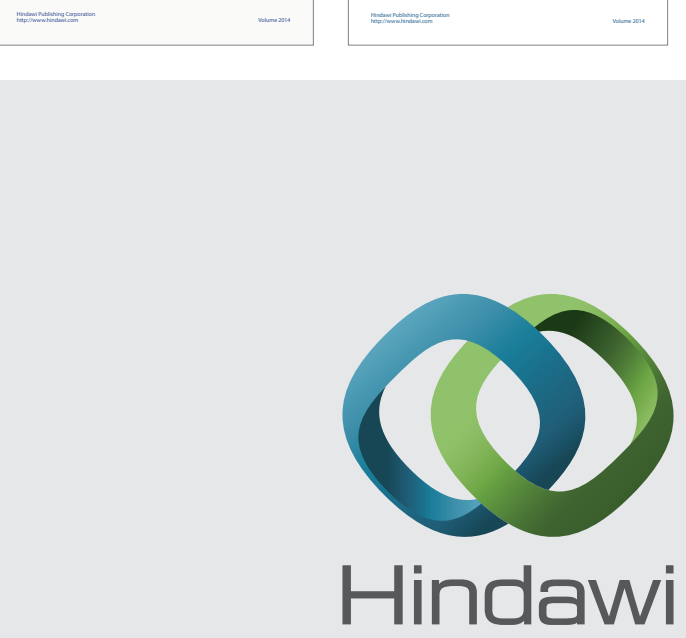

Submit your manuscripts at

http://www.hindawi.com
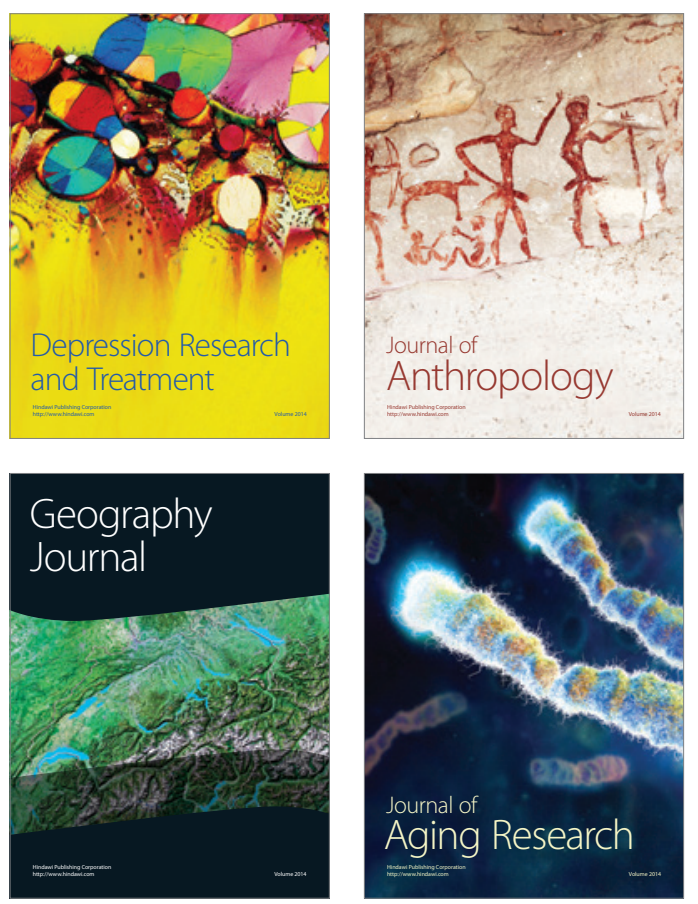
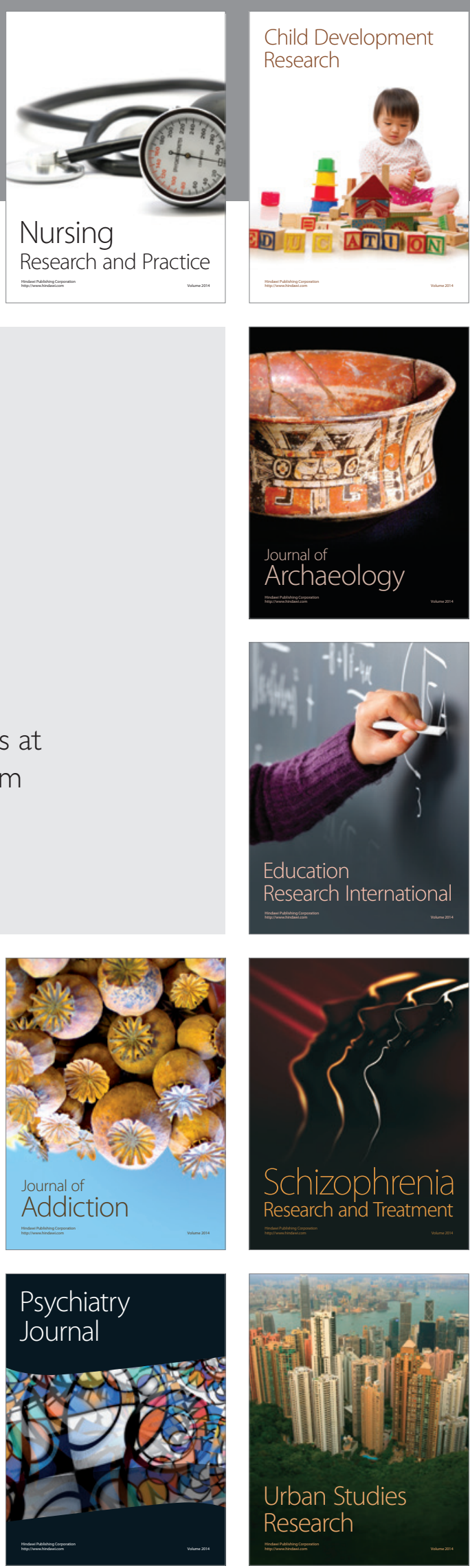